\title{
Type D personality is a predictor of prolonged acute brain dysfunction (delirium/coma) after cardiovascular surgery
}

Yujiro Matsuishi ${ }^{1}$, Nobutake Shimojo ${ }^{1}$, Takeshi Unoki ${ }^{2}$, Hideaki Sakuramoto ${ }^{3}$, Chiho Tokunaga ${ }^{4}$, Yasuyo Yoshino ${ }^{5}$, Haruhiko Hoshino ${ }^{1}$, Akira Ouchi ${ }^{1}$, Satoru Kawano ${ }^{1}$, Hiroaki Sakamoto ${ }^{4}$, Yuji Hiramatsu ${ }^{4}$ and Yoshiaki Inoue ${ }^{1 *}$ (D)

\begin{abstract}
Background: Previous studies have shown a relationship between delirium and depressive symptoms after cardiac surgery with distress personalities linking to negative surgical outcomes. The aim of the present study is to further investigate the association between patients with Type D (distressed) personality with regards to delirium after cardiac surgery.

Methods: We conducted a consecutive-sample observational cohort pilot study with an estimated 142 patients needed. Enrollment criteria included patients aged $\geq 18$ years who were undergoing planned cardiovascular, thoracic and abdominal artery surgery between October 2015 to August 2016 at the University of Tsukuba Hospital, Japan. All patients were screened by Type-D Personality Scale-14 (DS14) as well as the Hospital Anxiety and Depression Scale (HADS) the day before surgery. Following surgery, daily data was collected during recovery and included severity of organ dysfunction, sedative/analgesic exposure and other relevant information. We then evaluated the association between Type D personality and delirium/coma days (DCDs) during the 7-day study period. We applied regression and mediation modeling for this study.
\end{abstract}

Results: A total of 142 patients were enrolled in the present study and the total prevalence of delirium was found to be $34 \%$ and $26 \%$ of the patients were Type D. Non-Type D personality patients experienced an average of 1.3 DCDs during the week after surgery while Type D patients experienced 2.1 days over the week after surgery. Multivariate analysis showed that Type D personality was significantly associated with increased DCDs (OR:2.8, 95\%Cl:1.3-6.1) after adjustment for depressive symptoms and clinical variables. Additionally, there was a significant Type D x depression interaction effect (OR:1.7, 95\% Cl:1.2-2.2), and depressive symptoms were associated with DCDs in Type D patients, but not in non-Type D patients. Mediation modeling showed that depressive symptoms partially mediated the association of Type D personality with DCDs (Aroian test $=0.04$ ).

Conclusions: Type D personality is a prognostic predictor for prolonged acute brain dysfunction (delirium/coma) in cardiovascular patients independent from depressive symptoms and Type D personality-associated depressive symptoms increase the magnitude of acute brain dysfunction.

Keywords: Delirium, Delirium/coma days, Type D personality, Depression, Thoracic surgery, Intensive care units, Critical care

\footnotetext{
* Correspondence: yinoue@md.tsukuba.ac.jp

'Department of Emergency and Critical Care Medicine, Faculty of Medicine,

University of Tsukuba, Tsukuba, Ibaraki, Japan

Full list of author information is available at the end of the article
}

(c) The Author(s). 2019 Open Access This article is distributed under the terms of the Creative Commons Attribution 4.0 International License (http://creativecommons.org/licenses/by/4.0/), which permits unrestricted use, distribution, and reproduction in any medium, provided you give appropriate credit to the original author(s) and the source, provide a link to the Creative Commons license, and indicate if changes were made. The Creative Commons Public Domain Dedication waiver (http://creativecommons.org/publicdomain/zero/1.0/) applies to the data made available in this article, unless otherwise stated. 


\section{Background}

Delirium is a common post-surgical neuropsychological complication among cardiac patients and onset occurs rapidly due to the development of physiological abnormalities characterized by fluctuating course, attention deficits, disorganized thinking, and an altered level of consciousness [1].The prevalence of delirium within this post-surgical, cardiac patient population is reported to be between 26 to $52 \%$ [2]. This figure is in line with previous studies which report that preoperative cognitive impairment and depression in cardiac surgical patients are associated with greater risk of developing delirium [3, 4]. In addition, risk of delirium increases cumulatively with intraoperative and postoperative factors, such as longer cardiopulmonary bypass times [5] and/or use of benzodiazepine [6]. Importantly, delirium was independently associated with negative outcomes, such as higher mortality [7], decline in cognitive ability [8], increased length of stay and hospital readmissions [8]. However, outside of the prevalence, duration of delirium dose affect mortality [9]. Additionally, reports have measured delirium associated with terminal conditions [10] and from this insight, the concept of measuring both delirium and coma days was born [11-13]. The main concept is that psychiatric disorders can often manifest alongside physical ailments and even if the physical condition causes the initial psychiatric insult, ongoing depressive symptoms can enact a positive feedback loop to worsen the physical condition. To this end, previous studies reported that depressive symptoms are associated with delirium in cardiac patients [14]. However, a recent study reported that heart disease outcomes are not based on psychiatric condition alone but also patient personalities [15-19]. The distress personality (also known as Type D) is based on personality type and is defined by complex and highly negative emotions plus social inhibition [20] This total personality is associated with increase depressive symptoms [21]. Surprisingly, about $30 \%$ of cardiac surgery patients that carry this personality [22] suffer adverse consequences [23] and previous research showed a significant association between Type D personality and hard endpoint-adjusted hazard ratios (HR:2.24, 95\% CI [1.37-3.66]) in meta-analysis of 12 studies on 5341 patients [24]. Despite this initial evidence linking Type D personality with hazard ratios, a full explanation of the correlation between personality and postoperative delirium which lead to high mortality is still lacking. While previous research has reported that personality traits of neuroticism and conscientiousness are associated with delirium in hip fracture patients [25] another report found no association between Type D personality and delirium [26]. There is still a lack of associative evidence for Type $D$ personality, delirium and the mediating effects of depressive symptoms for this relationship. Some points of improvement were noted in this previous study allowing for closer examination into important factors such as the severity and duration of delirium/coma take account for better patient outcomes.

We hypothesize that a Type D personality affects postoperative delirium/coma days and by using regression and mediation modeling, the present study was able to revisit the association between Type $\mathrm{D}$ character and the development of postoperative delirium/coma days after cardiac surgery.

\section{Material and methods}

Patient selection

A list of enrolled and approved patients was obtained by operation room staff a week before surgery and enrollment criteria included patients aged $\geq 18$ years that were undergoing scheduled cardiovascular, thoracic and abdominal artery operations between October 2015 and August 2016. Patients were excluded if they had stroke, were deaf or otherwise unable to speak, or had current or previous major depression. This information was obtained from medical records. The Institutional Review Board (IRB) of the University of Tsukuba Affiliated Hospital approved the present study (H27-085) and written informed consent was obtained from patients prior to surgery.

\section{Data collection prior to surgery}

We recorded baseline preoperative factors, including age, sex, baseline medical history, and cardiac function, and calculated the European System score for Cardiac Operative Risk EvaluationII (EuroSCOREII) from these data [27] . EuroSCOREII is a cardiac risk score for predicting mortality after cardiac surgery that takes into account patient-related factors, cardiac-related factors, previous cardiac surgery, and operation-related factors. The validation of the EuroSCOREII with Japanese patients has been previously reported [27]. All patients underwent the following evaluations the day before the surgery: (a) the Type-D personality Scale-14 (DS14) [28]; (b) the Hospital Anxiety and Depression Scale (HADS) [29] and (c) the Mini-Mental State Examination (MMSE) [30]. The DS14 was specifically developed to assess Negative Affectivity (NA) and Social Inhibition (SI). This scale contains fourteen items and these subscales consist of seven items, and each item is rated from false (0) to true (4) on a 5-point Likert scale. Scores equal to or above 10 on both NA and SI were used to determine a Type D personality. HADS is a self-administered 
scale for the evaluation of anxiety and depression in non-psychiatric patients. Each item is rated on a 4-point Likert scale and increases measure degree of severity. In the present study, only the depressive HADS scale was used. The MMSE was used to assess presence and severity of cognitive impairment. The validation of the Japanese versions of DS14, HADS and MMSE has been previously reported [31-34]. DS14 and HADS were provided by paper and scoring was done after the experimental period, blinding the researchers to patient Type D status during testing.

\section{Intra- and post-operative data collection}

Intraoperative data, including aortic clamping time, was recorded. Post-operative daily data, including severity of organ dysfunction calculated by modified Sequential Organ Failure Assessment (mSOFA) and Benzodiazepine, Propofol, Dexmedetomidine dosage, were collected during ICU and general ward stays. Modified Sequential Organ Failure Assessment (mSOFA) is an assessment score calculated with $\mathrm{SpO} 2 /$ FiO2, liver function, cardiovascular, hypotension, central nervous system function, and renal creatinine levels. This system has been validated as a good predictor of post-operative mortality [35].

\section{Delirium assessment}

Delirium and coma were assessed using the Richmond Agitation - Sedation Scale (RASS) [36] and Confusion Assessment Method for the ICU (CAM-ICU) [37] twice daily for the 7-day study period. The assessments were all performed by IRB-approved researchers. Patients with RASS -4 and -5 were determined to be comatose and if delirium/coma was observed even once for a given day, it was noted that delirium/coma was prevalent for that particular day.

\section{Delirium/coma days (DCDs)}

DCDs are defined as days acute brain dysfunction (delirium and coma) within the study period. Delirium observation, however, took into account the comatose days to avoid lead time bias. Care was taken when recording both delirium and coma to avoid focusing on one of the DCDs conditions at the exclusion of the other (as seen in previous reports) which could have skewed or biased the data $[11,12]$.

\section{Statistical analysis}

\section{Sample size calculations}

Before this study, we conducted a month-long pilot study where a total of 22 patients, were enrolled and we observed a mean of $0.7(\mathrm{SD} \pm 1.4)$ delirium/coma days (DCDs) in the Type D personality group and a mean of $0.2(\mathrm{SD} \pm 0.3) \mathrm{DCDs}$ in the control group.
The sample size was calculated with the software $G$ * Power 3.1. Using Wilcoxon-Mann-Whitney testing, and effect size was $d=0.49$ based on the pilot study. We determined that a sample size of 142 patients would be required for a significance level $(\alpha)$ of 0.05 and test power $(1-\beta)$ of 0.80 .

\section{Regression modeling}

The outcomes of interest were DCDs within the 7-day study period. DCDs are defined as days with acute brain dysfunction (delirium and coma) within the study period. Because previous studies have noted a heavily skewed distribution of DCDs, we instead decided to use Proportional Odds Logistic Regression (POLR), which does not require the normal distribution, in examining the relationship between Type D personality and DCDs. Furthermore, we also adjusted for the following additional covariates chosen a priori in our model: EuroSCOREII, mSOFA without a central nervous system component, use of sedative medicine, and MMSE. EuroSCOREII for adjusting patient baseline characteristics including sex, age, history of complications, and intraoperative factors including urgency and intervention procedures. We used mSOFA for adjusting for daily severity of the patient. As central nervous system (CNS) components would be correlated with the outcome of interest we excluded this component to protect the integrity of our analysis. Additionally, The variance inflation factor (VIF) were observed to assess multicollinearity among the variables. As previous studies reported [38, 39], we tested continuous values of SI and NA (which are components of Type D personality) independently as a sub-analysis.

\section{Interaction}

As Type D personality and depressive symptoms are generally considered co-morbid, and previous studies reported that having these two factors suspected to inflate bad outcomes for cardiac patients [40, 41]. Therefore, we attempted to construct an interaction model. Interaction modeling can analyze the relationship of the inflation between two factors (covariates) for outcome of the interest. Although the basic assumption of regression modeling is the independence of each factor, we suspected a significant interaction and therefore used a two-step process where we first constructed an isolated main effect model (model 1) then iteratively included interaction modeling (model 2). In model 2, the odds ratio of the main effect (Type D personality and depressive symptoms) was not significant, possibly due to the ability to capture only a segment of the main effect. 


\section{Mediation modeling}

To determine the mediating effect of depressive symptoms on the relationship between Type D personality and DCDs, mediation analyses were conducted using the Baron and Kenny approach [42] (bootstrapping method and Aroian testing) [43] and adjusted for the same covariate factors in regression modeling. All statistical analyses were performed using SPSS version 25 (SPSS, Inc., Chicago, IL).

\section{Results}

\section{Patient characteristics}

From October 2015 to August 2016, we enrolled a total of 142 patients (see Fig. 1 illustrating participant flow).

Of the 174 patients, the following two groups were excluded from the study: A) 16 patients: 2 deaf or unable to speak, 2 could not speak Japanese and 12 had stroke B) 16 patients that freely exercised their legal right to refuse participation. Table 1 presents baseline patient study characteristics.

$45 \%$ of the patient takes valve surgery and the median age at enrollment was $67( \pm 14)$ and $63 \%$ of the patients were male. The average EuroSCOREII was $2.0( \pm 2.0)$ and the average of 7-days modified Sequential Organ Failure Assessment was 3.5 ( \pm 2.1). Non-Type D personality patients experienced coma days average of $0.8 \pm 1.1$ during the week after surgery while Type D patients experienced $0.9 \pm 1.0$, and Non-Type D personality patients experienced a delirium average of $0.4 \pm 0.8$ during the week after surgery while Type D patients experienced $1.1 \pm 1.5$, thus Non-Type D personality patients experienced $1.3 \pm 1.6$ DCDs during the week after surgery while Type D patients experienced 2.1 \pm 1.9 DCDs over the week after surgery (Fig. 2). All patients survived during the study period. Out of the 49 patients (34\%) with

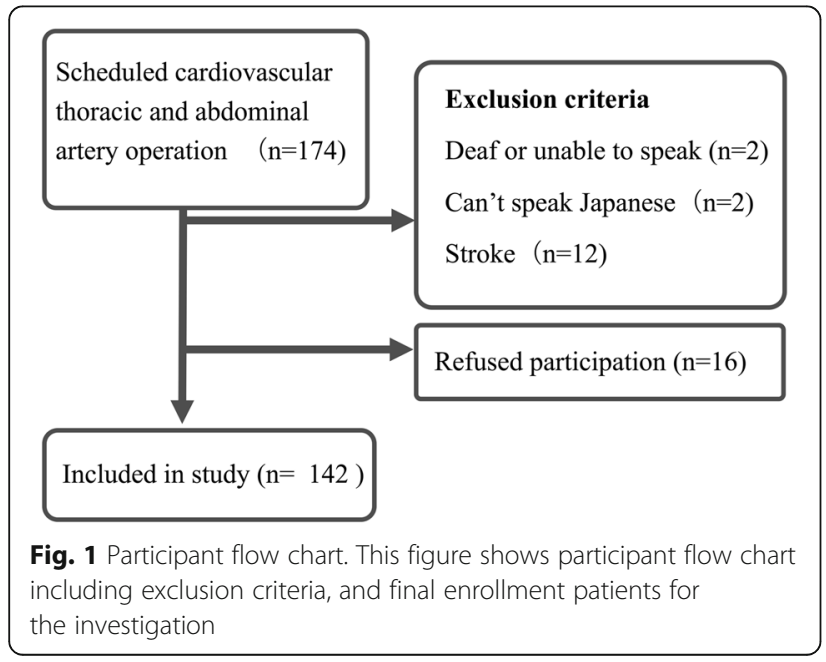

delirium in total population and 32 patients $(30 \%)$ in Non-Type D personality 17 patients (45\%) in Type D personality patients experienced delirium, 37 patients (26\%) were found to have a Type D personality.

\section{Regression modeling}

VIF was less than 3. Therefore, multicollinearity was considered not to be problematic. Type D personality factors [odds ratio $(\mathrm{OR})=2.8,95 \%$ confidence interval $(\mathrm{CI})=$ 1.3-6.1], HADS-Depression $(\mathrm{OR}=1.1,95 \% \mathrm{CI}=1.0$ 1.3), mSOFA ( $\mathrm{OR}=1.7,95 \% \mathrm{CI}=1.3-2.2)$, Benzodiazepine $(\mathrm{OR}=9.8,95 \% \mathrm{CI}=2.4-40.3)$ and Propofol $(\mathrm{OR}=1.1,95 \% \mathrm{CI}=1.0-1.2)$ were associated with significantly increased DCDs (Table 2). This indicates that these factors were independently associated with prolonged acute brain dysfunction in the 7-day post-operative period. We also tested continuous values of SI and NA (which are components of Type $\mathrm{D}$ personality) independently as a sub-analysis NA $(\mathrm{OR}=1.09,95 \% \mathrm{CI}=1.03-1.15)$ and $\mathrm{SI}(\mathrm{OR}=1.05$, 95\% $\mathrm{CI}=1.0-1.1)$ themselves were also associated with significantly decreased DCDs (Table 3 ) and NA and SI interaction was not significant. (OR $=0.9,95 \%$ $\mathrm{CI}=0.9-1.0)($ Table 4).

\section{Moderator model}

Model 2 for DCDs included interaction between Type $\mathrm{D}$ personality and depressive symptoms, and this interaction was found to be significant (Type D personality $\times$ depressive symptoms: $\mathrm{OR}=1.7,95 \% \mathrm{CI}=$ 1.2-2.2). (Table 2).

This interaction effect indicates that Type D personality moderated the association of depressive symptoms with DCDs; i.e., depressive symptoms had a deleterious effect in terms of prolonged brain dysfunction among Type $\mathrm{D}$ patients, but depressive symptoms were not associated with DCDs in non-Type D patients (Fig. 3).

\section{Mediation model}

The mediation analyses involved Type D personality (X; independent variable), depressive symptoms ( $\mathrm{M}$; mediator), and DCDs (Y; dependent variable) and were adjusted for the same covariate factors in regression modeling (Fig. 4). The analysis was performed according to Baron and Kenny's method [42] as follows:

First, Type D personality $(\mathrm{X})$ significantly predicts $\operatorname{DCDs}(Y)(\beta=0.93 ; p<0.01)$.

Second, Type $\mathrm{D}$ personality $(\mathrm{X})$ significantly predicts depressive symptoms $(\mathrm{M})(\beta=1.35 ; p<0.01)$.

Third, in regression analysis, both Type $\mathrm{D}$ personality $(\mathrm{X})$ and depressive symptoms $(\mathrm{M})$ are predictors for $\operatorname{DCDs}(\mathrm{Y})(\beta=0.78 ; p<0.01),(\beta=0.109 ; p=0.02)$. 
Table 1 Baseline characteristics of study patients

\begin{tabular}{|c|c|c|c|}
\hline variable & Total population $N=142$ & Type D personality $N=37$ & Non-Type $D$ personality $N=105$ \\
\hline Age $\pm S D$ & $67 \pm 14$ & $64 \pm 13$ & $67 \pm 14$ \\
\hline Male n (\%) & $90(63)$ & $24(64)$ & $66(62)$ \\
\hline \multicolumn{4}{|l|}{ Surgical procedure n (\%) } \\
\hline CABG & $26(18)$ & $7(18)$ & $19(18)$ \\
\hline CABG+Valve surgery & $10(7)$ & $2(5)$ & $8(7)$ \\
\hline Valve surgery & $65(45)$ & $14(37)$ & $51(48)$ \\
\hline Thoracic blood vessel replacement & $7(4)$ & $3(8)$ & $4(3)$ \\
\hline Thoracic blood vessel replacement+VALVE surgery & $6(4)$ & $1(2)$ & $5(4)$ \\
\hline Abdominal blood vessel replacement & $5(3)$ & $1(2)$ & $4(3)$ \\
\hline Endovascular aortic repair & $16(11)$ & $5(13)$ & $11(10)$ \\
\hline ASDNSD closer & $2(1)$ & $1(2)$ & $1(1)$ \\
\hline Heart tumor resection & $3(2)$ & $2(5)$ & $1(1)$ \\
\hline Ventricular aneurysm resection & $2(1)$ & $1(2)$ & $1(1)$ \\
\hline MMSE \pm SD & $28 \pm 1.52$ & $28 \pm 1.50$ & $28 \pm 1.53$ \\
\hline Depressive symptom ${ }^{a} \pm S D$ & $1.9 \pm 2.7$ & $3.0 \pm 2.9$ & $1.6 \pm 2.5$ \\
\hline \multicolumn{4}{|l|}{ DS 14} \\
\hline Negative Affectivity (NA) & $6.6 \pm 6.0$ & $14.8 \pm 4.2$ & $3.7 \pm 3.2$ \\
\hline Social Inhibition (SI) & $8.7 \pm 6.6$ & $16.0 \pm 4.7$ & $6.2 \pm 5.1$ \\
\hline EurOSCOREII \pm SD & $2.0 \pm 2.0$ & $1.7 \pm 1.5$ & $2.1 \pm 2.1$ \\
\hline Aortic clamping times, min (IQR) & $135(0,206)$ & $136(34,214)$ & $135(0,208)$ \\
\hline$m S O F A^{b} \pm S D$ & $3.5 \pm 2.1$ & $3.4 \pm 1.9$ & $3.5 \pm 2.2$ \\
\hline Benzodiazepine $(\mathrm{mg} / \mathrm{kg} / \text { day })^{\mathrm{b}} \pm \mathrm{SD}$ & $0.06 \pm 0.5$ & $0.06 \pm 0.41$ & $0.06 \pm 0.53$ \\
\hline Propofol (mg/kg/day) ${ }^{\mathrm{b}} \pm \mathrm{SD}$ & $2.8 \pm 6.6$ & $3.0 \pm 7.3$ & $2.3 \pm 4.1$ \\
\hline Dexmedetomidine $(\mu \mathrm{g} / \mathrm{kg} / \text { day })^{\mathrm{b}} \pm \mathrm{SD}$ & $0.8 \pm 3.0$ & $0.6 \pm 1.2$ & $0.9 \pm 3.4$ \\
\hline Prevalence of delirium n (\%) & $49(34)$ & $17(45)$ & $32(30)$ \\
\hline Delirium/coma days \pm SD & $1.5 \pm 1.7$ & $2.1 \pm 1.9$ & $1.3 \pm 1.6$ \\
\hline Coma days \pm SD & $0.9 \pm 1.1$ & $0.9 \pm 1.0$ & $0.8 \pm 1.1$ \\
\hline Delirium days \pm SD & $0.6 \pm 1.0$ & $1.1 \pm 1.5$ & $0.4 \pm 0.8$ \\
\hline
\end{tabular}

a: measured by Hospital Anxiety and Depression Scale (HADS)

b: used average of 7 days

IQR interquartile range, SD standard deviation, MMSE mini-mental state examination, EuroSCOREII European System for Cardiac Operative Risk Evaluation II, mSOFA modified Sequential Organ Failure Assessment

The subsequent Aroian test, which tests the statistically significant difference in results between univariate and regression analyses with respect to Type D personality $(\mathrm{X})$ for DCFDs $(\mathrm{Y})$, was significantly different $(p=0.04)$.

Based on the above analysis, our present findings show that Type $\mathrm{D}$ personality is an independent predictor of DCDs and that depressive symptoms had a partial mediating effect on the relationship between Type D personality and DCDs after adjustment.

\section{Discussion}

The present study is the first to demonstrate that Type D personality patients experience longer acute brain dysfunction (measured as delirium/coma days) during 7 days after operation, after adjusting for severity and various predicting factors. Although a previous study had shown that the prevalence of Type D personality is relatively high (46\%) in Japan among healthy subjects [44], the present study is the first to show that the Japanese prevalence rates are comparable to European cardiac surgery patients [22]. One possible reason for the difference between the current findings and the previous Japanese study could be that the earlier study was conducted in the rural areas of Japan, which have a higher population of the elderly, thus inflating the prevalence of Type D personality.

Several previous studies showed that Type D personality was associated with depressive symptoms [21, 


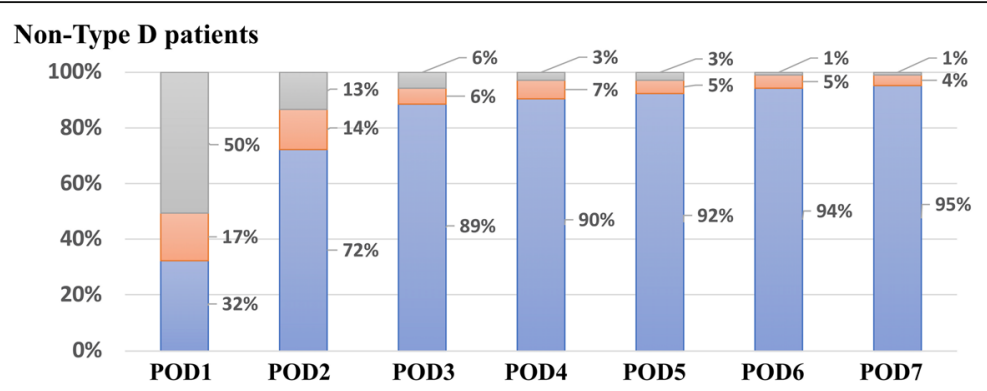

Type D patients

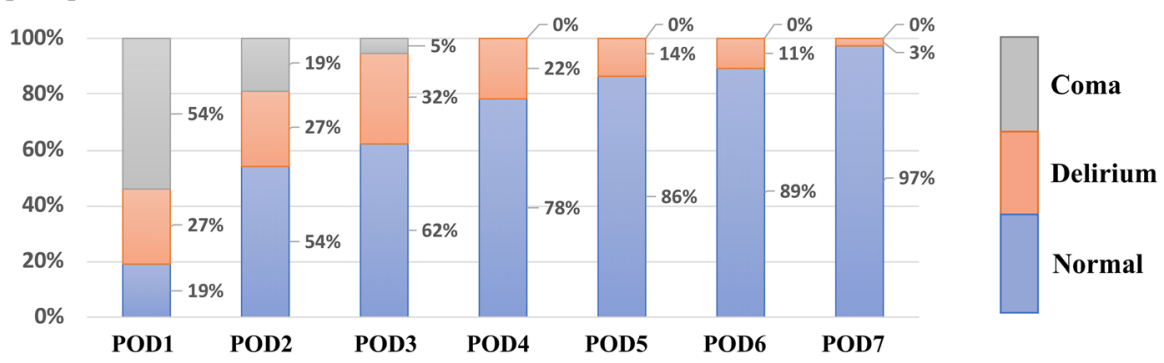

POD: Post operative day

Interaction between type $D$ personality and time: $p=0.908$ analyzed by generalized liner mixed model.

Fig. 2 Distribution of normal, delirium, and coma days, stratified by Type D personality. This is the distribution of normal, coma, delirium days for normal and Type D personality

45] and these were in turn were associated with delirium $[3,46]$. Our present results are in line with these earlier results but we differed in our methods by employing regression (including interaction) models and mediation modeling to analyze statistical significance within our findings that depressive symptoms have a partial mediating effect between Type D personality and acute brain dysfunction during the 7-day period after surgery.

Based on these analyses, we found a theoretical relationship between distressed personality and depressive symptoms [47]. Depressive symptoms can be said

Table 2 Regression model for prolonged delirium/coma days

\begin{tabular}{|c|c|c|c|c|}
\hline & Multivariate model $1 \mathrm{OR}(95 \% \mathrm{Cl})^{a}$ & VIF & Multivariate model 2 OR $(95 \% \mathrm{Cl})^{a}$ & VIF \\
\hline EurOSCOREII & $1.1(0.9-1.3)$ & 1.3 & $1.1(0.9-1.3)$ & 1.3 \\
\hline MMSE & $0.9(0.7-1.1)$ & 1.1 & $0.9(0.7-1.1)$ & 1.1 \\
\hline Type D personality (Present or not) & $2.8(1.3-6.1)^{*}$ & 1.0 & $2.4(5.4-1.0)^{*}$ & 1.1 \\
\hline Depressive symptoms ${ }^{b}$ & $1.1(1.0-1.3)^{*}$ & 1.1 & $0.9(0.8-1.1)$ & 1.7 \\
\hline Aortic clamping time & $0.9(0.9-1.0)$ & 1.4 & $0.9(0.9-1.0)$ & 1.4 \\
\hline mSOFA ${ }^{c}$ & $1.7(1.3-2.2)^{*}$ & 1.7 & $1.7(1.3-2.7)^{*}$ & 1.7 \\
\hline Benzodiazepine $^{d}$ & $9.8(2.4-40.3)^{*}$ & 1.1 & $16.1(3.7-69.8)^{*}$ & 1.1 \\
\hline Propofol ${ }^{d}$ & $1.1(1.0-1.2)^{*}$ & 1.9 & $1.1(1.1-1.3)^{*}$ & 1.9 \\
\hline Dexmedetomidine ${ }^{e}$ & $1.1(0.9-1.2)$ & 1.7 & $1.1(0.9-1.2)$ & 1.7 \\
\hline \multicolumn{3}{|c|}{ Type D personality $\times$ Depressive symptom ${ }^{f}$} & $1.7(1.2-2.2)^{*}$ & 1.6 \\
\hline
\end{tabular}

a: $P$ values obtained from Ordered Logistic Regression ${ }^{*} P$ value $<0.05$

b: measured by Hospital Anxiety and Depression Scale (HADS)

c: Exclude GCS, used average of 7 days

$\mathrm{d}$ : Used average of 7 days. $\mathrm{mg} / \mathrm{day} / \mathrm{kg}$

e: Used average of 7 days. $\mu \mathrm{g} /$ day $/ \mathrm{kg}$

f: Centering was performed

MMSE mini-mental state examination, EuroSCOREIl European System for Cardiac Operative Risk Evaluation II, mSOFA modified Sequential Organ Failure Assessment 
Table 3 Sub-analysis of each tendency of regression model for prolonged delirium/coma days

\begin{tabular}{|c|c|c|c|c|}
\hline & Multivariate model $3 \mathrm{OR}(95 \% \mathrm{Cl})^{a}$ & VIF & Multivariate model 4 OR $(95 \%$ Cl) & VIF \\
\hline EuroSCOREII & $1.1(0.9-1.3)$ & 1.3 & $1.1(0.9-1.3)$ & 1.2 \\
\hline MMSE & $0.9(0.7-1.1)$ & 1.0 & $0.9(0.7-1.3)$ & 1.1 \\
\hline Negative Affectivity (NA) & $1.09(1.03-1.15)^{*}$ & 1.0 & & \\
\hline Social Inhibition (SI) & & & $1.05(1.0-1.1)^{*}$ & 1.0 \\
\hline Depressive symptoms ${ }^{\mathrm{b}}$ & $1.1(1.0-1.3)^{*}$ & 1.1 & $1.1(1.0-1.3)^{*}$ & 1.1 \\
\hline Aortic clamping time & $0.9(0.9-1.0)$ & 1.0 & $0.9(0.9-1.0)$ & 1.0 \\
\hline $\mathrm{mSOFA}^{\mathrm{c}}$ & $1.7(1.3-2.2)^{*}$ & 1.6 & $1.6(1.2-2.1)^{*}$ & 1.6 \\
\hline Benzodiazepine $^{d}$ & $9.9(2.4-40.2)^{*}$ & 1.0 & $9.8(2.3-40.9)^{*}$ & 1.0 \\
\hline Propofol $^{d}$ & $1.1(1.0-1.2)^{*}$ & 1.8 & $1.1(1.0-1.2)^{*}$ & 1.8 \\
\hline Dexmedetomidine $e^{e}$ & $1.1(0.9-1.2)$ & 1.7 & $1.1(0.9-1.3)$ & 1.7 \\
\hline
\end{tabular}

a: $P$ values obtained from Ordered Logistic Regression $* P$ value $<0.05$

b: measured by Hospital Anxiety and Depression Scale (HADS)

c: Exclude GCS, used average of 7 days

$\mathrm{d}$ : Used average of 7 days. $\mathrm{mg} / \mathrm{day} / \mathrm{kg}$

e: Used average of 7 days. $\mu \mathrm{g} / \mathrm{day} / \mathrm{kg}$

MMSE mini-mental state examination, EuroSCOREII European System for Cardiac Operative Risk Evaluation II, mSOFA modified Sequential Organ Failure Assessment

to have an additive deleterious effect on DCDs when combined with Type D personality. Thus, we should be aware that patients with Type D personalities may experience delirium and brain dysfunction after cardiac surgery and should be monitored carefully for depressive symptoms. Depressive symptoms are a

Table 4 Sub-analysis of each tendency's regression modeling interaction for prolonged delirium/coma days

\begin{tabular}{lll}
\hline & $\begin{array}{l}\text { Multivariate model 5 } \\
\text { OR }(95 \% \text { Cl) }\end{array}$ & VIF \\
\hline EuroSCOREII & $1.1(0.9-1.3)$ & 1.3 \\
MMSE & $0.9(0.9-1.1)$ & 1.1 \\
Negative Affectivity (NA) & $1.0(1.0-1.1)^{*}$ & 2.5 \\
Social Inhibition (SI) & $1.0(0.9-1.0)$ & 1.8 \\
Negative Affectivity & $0.9(0.9-1.0)$ & 1.7 \\
$($ NA) $\times$ Social Inhibition (SI) & & 1.1 \\
Depressive symptoms & $1.1(1.0-1.3)^{*}$ & 1.0 \\
Aortic clamping time $^{\mathrm{b}}$ & $0.9(0.9-1.0)$ & 1.6 \\
mSOFA $^{\mathrm{d}}$ & $1.7(1.3-2.2)^{*}$ & 1.0 \\
Benzodiazepine $^{\mathrm{e}}$ & $11(2.6-46.2)^{*}$ & 1.8 \\
Propofol $^{\mathrm{e}}$ & $1.1(1.0-1.2)^{*}$ & 1.7 \\
Dexmedetomidine $^{\mathrm{f}}$ & $1.1(0.9-1.3)$ &
\end{tabular}

a: $P$ values obtained from Ordered Logistic Regression $* P$ value $<0.05$

b: Centering was performed

c: measured by Hospital Anxiety and Depression Scale (HADS)

d: Exclude GCS, used average of 7 days

e: Used average of 7 days. $\mathrm{mg} /$ day $/ \mathrm{kg}$

f: Used average of 7 days. $\mu \mathrm{g} /$ day $/ \mathrm{kg}$

MMSE mini-mental state examination, EuroSCOREII European System for Cardiac Operative Risk Evaluation II, mSOFA modified Sequential Organ Failure Assessment solid predictive factor for delirium [48]; however, there is no knowledge of the association between Type D personality and depressive symptoms for prolonged acute brain dysfunction. We assume that Type D personality patients might underreport their symptoms even if they are in such an at-risk population for depression. Therefore, this propensity to underreport depressive symptoms underscores the need for solid evaluative tools to screen out Type D personalities from patient pools for more intensive monitoring to assist in their recoveries. We suggest further researches should focus on this interaction and mediation when studies for acute brain dysfunction include Type D personality or depressive symptoms as a factor. We also observed a NA and SI-independent effect for DCDs. From this result, we assumed that each component of the Type D personality worsens acute brain dysfunction after cardiovascular surgery. Previous research showed that SI modulates the effect of NA on cardiac prognosis following percutaneous coronary intervention [49]. Further research with a proper sample size is needed to check for any modulating effect for acute brain dysfunction.

Another potential mechanism through which Type D personality might have a negative influence on acute brain dysfunction may include inflammation and endothelial dysfunction. Previous observational studies showed that Type D personality was significantly associated with increased levels of IL-6 and TNF- $\alpha$ [50, 51]. In addition, another study showed that Type D personality is significantly associated with elevation of another pro-inflammatory marker, C-reactive protein [52], in a 


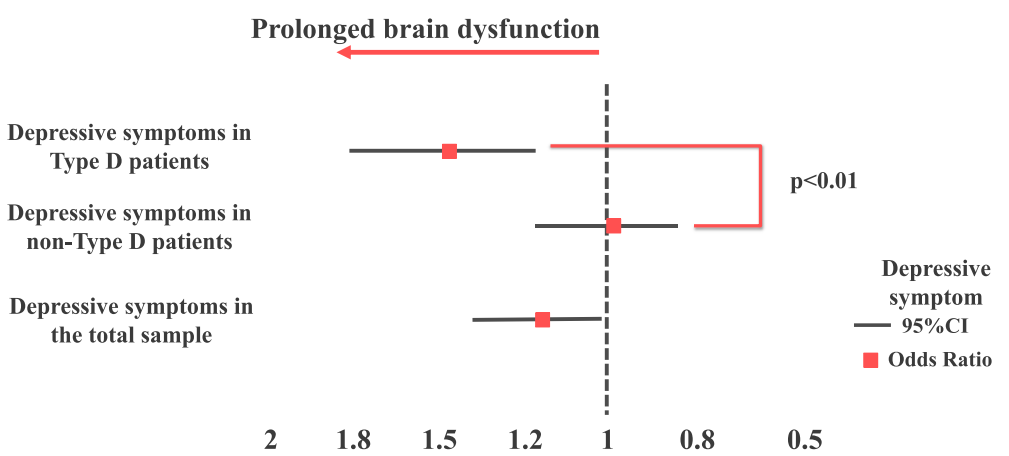

Fig. 3 Association of depressive symptoms with prolonged brain dysfunction, stratified by Type D personality. The interactive effect of Type D personality and depressive symptoms on DCDs. Adjusted for the covariate factors used in regression modeling

large, population-based study [45]. However, not only is Type D personality associated with inflammation, it is also linked to endothelial dysfunction. Interestingly, a previous study has reported that Type D personality is associated with decreased endothelial progenitor cells in patients with heart failure [53] and a recent study in patients with coronary artery disease showed that the association of Type D personality with endothelial dysfunction was robust across time [54]. It was already shown that inflammation biomarkers and these receptors associated with onset of delirium [55] and endothelial dysfunction associated with acute brain dysfunction during critical illness [56]. Further research is needed to explore whether the underlying mechanism of the observed relationship between Type D personality and delirium could be neural inflammation and/or endothelial factors.

\section{Limitation}

There are several limitations in the present study. First, since this study is a cross-sectional design, the direction of the mediation between Type $\mathrm{D}$ personality and depressive symptoms cannot be confirmed. Second, the Type D personality scale (DS14) and depressive symptom scale (HADS) might have some overlapping questions. Additionally, the stress and dysphoria that naturally results from impending surgery might have skewed testing that was done the day before surgery. However, a previous study showed that Type D personality and depression are distinct manifestations of psychological distress [57]. Hence, we think that our current finding that shows a cross between independent variable and mediating effect might be valid. Third, despite the good response rate $(90 \%)$, the non-consenting

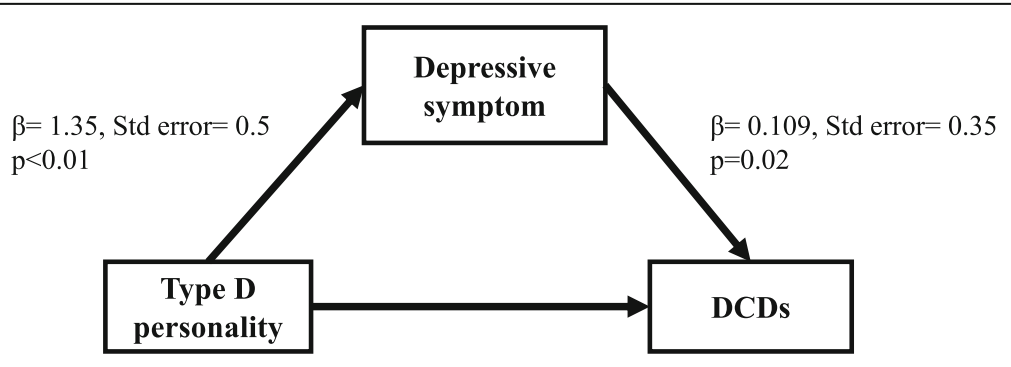

Direct effect: $\beta=0.78$, Std error $=0.20$ $\mathrm{p}<0.01$

Total effect: $\quad \beta=0.93$, Std error $=0.21 \quad$ Aroian's test $\mathrm{p}<0.01 \quad \mathrm{p}=0.04$

The mediation effect of depressive symptoms regarding the association of Type D personality with DCDs, adjusted for the same covariates used in regression modeling.

Fig. 4 Mediation model for delirium/coma days. The mediation effect of depressive symptoms regarding the association of Type D personality with DCDs, adjusted for the same covariates used in regression modeling 
patients (who were not assessed) may have refused consent because of a higher level of depressive symptoms, leading to some bias in the results.

\section{Conclusion}

Type $\mathrm{D}$ personality is a prognostic predictor for prolonged acute brain dysfunction (delirium/coma) in cardiovascular patients independent from depressive symptoms. Furthermore, Type D personality-associated depressive symptoms increase the magnitude of acute brain dysfunction.

\section{Abbreviations}

CAM-ICU: Confusion Assessment Method for the ICU; CNS: Central nerve system; DCDs: Delirium/coma days; DS14: Type-D personality Scale-14; EuroSCORE II: European System score for Cardiac Operative Risk Evaluation II; HADS: Hospital Anxiety and Depression Scale; IL-6: Interleukin-6; MMSE: MiniMental State Examination; mSOFA: Modified Sequential Organ Failure Assessment; NA: Negative Affectivity; POLR: Proportional Odds Logistic Regression; RASS: Richmond Agitation - Sedation Scale; SD: Standard deviation; SI: Social Inhibition; TNF-a: Tumor Necrosis Factor a; VIF: The variance inflation factor

\section{Acknowledgments}

We would like to thank all of the patients for participating in this study. We would also like to thank Dr. Bryan J. Mathis of the University of Tsukuba Medical English Communication Center for critical reading of this manuscript.

\section{Funding}

No funding received.

\section{Availability of data and materials}

The datasets used and/or analyzed during the present study are available from the corresponding author on reasonable request.

\section{Authors' contributions}

YM designed the study and carried out sample collection, data analysis, and wrote the manuscript. NS, UT, HS1, SK and YI participated in designing study. $\mathrm{YY}, \mathrm{HH}$ and $\mathrm{AO}$ participated in sample collection. CT, HS2 and $\mathrm{YH}$ support clinical aspects including informed consent. All authors read and approved the final manuscript.

\section{Ethics approval and consent to participate}

The Institutional Review Board (IRB) of the University of Tsukuba Affiliated Hospital approved the present study (-H27-085) and written informed consent was obtained from patients prior to surgery.

\section{Consent for publication}

Not applicable.

\section{Competing interests}

The authors declare that they have no competing interests.

\section{Publisher's Note}

Springer Nature remains neutral with regard to jurisdictional claims in published maps and institutional affiliations.

\section{Author details}

'Department of Emergency and Critical Care Medicine, Faculty of Medicine, University of Tsukuba, Tsukuba, Ibaraki, Japan. ${ }^{2}$ Department of Adult Health Nursing, School of Nursing, Sapporo City University, Sapporo, Japan. ${ }^{3}$ Adult Health Nursing, College of Nursing, Ibaraki Christian University, Hitachi, Ibaraki, Japan. ${ }^{4}$ Department of Cardiovascular Surgery, Faculty of Medicine, University of Tsukuba, Tsukuba, Ibaraki, Japan. ${ }^{5}$ Department of Nursing, Kanto Gakuin University College of Nursing, Yokohama, Kanagawa, Japan.
Received: 25 August 2018 Accepted: 16 April 2019

Published online: 02 May 2019

\section{References}

1. American Psychiatric Association. Diagnostic and Statistical Manual of Mental Disorders : DSM-5. Washington: American Psychiatric Publishing; 2014

2. Brown $\mathrm{CH}$. Delirium in the cardiac surgical ICU. Curr Opin Anaesthesiol. 2014:27(2):117-22.

3. Kazmierski J, Kowman M, Banach M, et al. Incidence and predictors of delirium after cardiac surgery: results from the IPDACS study. J Psychosom Res. 2010;69(2):179-85.

4. Stransky M, Schmidt C, Ganslmeier $P$, et al. Hypoactive delirium after cardiac surgery as an independent risk factor for prolonged mechanical ventilation. J Cardiothorac Vasc Anesth. 2011;25(6):968-74.

5. Andrejaitiene J, Sirvinskas E. Early post-cardiac surgery delirium risk factors. Perfusion. 2012;27(2):105-12

6. McPherson JA, Wagner CE, Boehm LM, et al. Delirium in the cardiovascular ICU: exploring modifiable risk factors. Crit Care Med. 2013;41(2):405-13.

7. Martin B-J, Buth KJ, Arora RC, Baskett RJF. Delirium: a cause for concern beyond the immediate postoperative period. Ann Thorac Surg. 2012;93(4): 1114-20.

8. Koster S, Hensens AG, Schuurmans MJ, Van Der Palen J. Consequences of delirium after cardiac operations. Ann Thorac Surg. 2012;93(3):705-11.

9. Bellelli G, Mazzola P, Morandi A, et al. Duration of postoperative delirium is an independent predictor of 6-month mortality in older adults after hip fracture. J Am Geriatr Soc. 2014;62(7):1335-40.

10. Pandharipande $P$, Jackson J, Ely EW. Delirium: acute cognitive dysfunction in the critically ill. Curr Opin Crit Care. 2005;11(4):360-8.

11. Inoue S, Vasilevskis EE, Pandharipande PP, et al. The impact of Lymphopenia on delirium in ICU patients. PLoS One. 2015;10(5):1-11.

12. Page VJ, Ely EW, Gates S, et al. Eff ect of intravenous haloperidol on the duration of delirium and coma in critically ill patients ( Hope-ICU ): a randomised, double-blind, placebo-controlled trial. Lancet Oncol. 2013;1(7): 515-23.

13. Pandharipande PP, Sanders RD, Girard TD, et al. Effect of dexmedetomidine versus lorazepam on outcome in patients with sepsis: an apriori-designed analysis of the MENDS randomized controlled trial. Crit Care (London, England). 2010;14(2):R38.

14. Rudolph JL, Jones RN, Levkoff SE, et al. Derivation and validation of a preoperative prediction rule for delirium after cardiac surgery. Circulation. 2009;119(2):229-36.

15. Denollet J, Pedersen SS, Vrints CJ, Conraads VM. Usefulness of type D personality in predicting five-year cardiac events above and beyond concurrent symptoms of stress in patients with coronary heart disease. Am Cardiol. 2006:97(7):970-3.

16. Denollet J, Sys SU, Stroobant N, Rombouts H, Gillebert TC, Brutsaert DL. Personality as independent predictor of long-term mortality in patients with coronary heart disease. Lancet (London, England). 1996;347(8999):417-21.

17. Kupper N, Denollet J, Type D. Personality as a risk factor in coronary heart disease: a review of current evidence. Curr Cardiol Rep. 2018;20(11):104.

18. Williams L, O'Connor RC, Grubb N, O'Carroll R. Type D personality predicts poor medication adherence in myocardial infarction patients. Psychol Health. 2011:26(6):703-12.

19. Williams L, O'Carroll RE, O'Connor RC. Type D personality and cardiac output in response to stress. Psychol Health. 2009:24(5):489-500.

20. Denollet J, Van Heck GL. Psychological risk factors in heart disease: what Type D personality is (not) about. J Psychosom Res. 2001;51(3):465-8.

21. Spindler $H$, Kruse C, Zwisler AD, Pedersen SS. Increased anxiety and depression in danish cardiac patients with a type D personality: crossvalidation of the type D scale (DS14). Int J Behav Med. 2009;16(2):98-107.

22. Dannemann $S$, Matschke $K$, Einsle $F$, et al. Is type-D a stable construct? An examination of type-D personality in patients before and after cardiac surgery. J Psychosom Res. 2010;69(2):101-9.

23. Lin I-M, Wang S-Y, Chu I-H, et al. The Association of Type D personality with heart rate variability and lipid profiles among patients with coronary artery disease. Int J Behav Med. 2017;24(1):101-9.

24. Grande G, Romppel M, Barth J. Association between type D personality and prognosis in patients with cardiovascular diseases: a systematic review and meta-analysis. Ann Behav Med. 2012;43(3):299-310. 
25. Shin JE, Kyeong S, Lee JS, et al. A personality trait contributes to the occurrence of postoperative delirium: a prospective study. BMC Psychiatry. 2016;16(1):1-13

26. Tully PJ, Baker RA, Winefi HR, Turnbull DA. Depression, anxiety disorders and Type D personality as risk factors for delirium after cardiac surgery. Aust N Z J Psychiatry. 2010:44(May):1005-11.

27. Nashef SAM, Roques F, Sharples LD, et al. Euroscore II. Eur J Cardio-thoracic Surg. 2012;41(4):734-45.

28. Denollet J. DS14: standard assessment of negative affectivity, social inhibition, and Type D personality. Psychosom Med. 2005;67(1):89-97.

29. Zigmond AS, Snaith RP. The hospital anxiety and depression scale. Acta Psychiatr Scand. 1983;67(6):361-70.

30. Folstein MF, Folstein SE, McHugh PR. "Mini-mental state". A practical method for grading the cognitive state of patients for the clinician. J Psychiatr Res. 1975;12(3):189-98.

31. Ideno Y, Takayama M, Hayashi K, Takagi H, Sugai Y. Evaluation of a Japanese version of the mini-mental state examination in elderly persons. Geriatr Gerontol Int. 2012;12(2):310-6.

32. Shigemori K, Ohgi S, Okuyama E, Shimura T, Schneider E. The factorial structure of the mini mental state examination (MMSE) in Japanese dementia patients. BMC Geriatr. 2010;10:36.

33. Ishihara S, Uchibori T, Imai A, Makita S. Development of the Japanese version of Type D scale for patients with coronary heart disease. Japanese J Heal Psychol. 2015;27:177-84

34. Higashi A, Yashiro $H$, Kiyota $K$, et al. Validation of the hospital anxiety and depression scale in a gastro-intestinal clinic. Nihon Shokakibyo Gakkai Zasshi. 1996;93(12):884-92.

35. Grissom CK, Brown SM, Kuttler KG, et al. A modified sequential organ failure assessment score for critical care triage. Disaster Med Public Health Prep. 2010;4(4):277-84.

36. Sessler CN, Gosnell MS, Grap MJ, et al. The Richmond agitation-sedation scale: validity and reliability in adult intensive care unit patients. Am J Respir Crit Care Med. 2002;166(10):1338-44.

37. Ely EW, Margolin R, Francis J, et al. Evaluation of delirium in critically ill patients: validation of the confusion assessment method for the intensive care unit (CAM-ICU). Crit Care Med. 2001:29(7):1370-9.

38. Stevenson C, Williams L. Type D personality, quality of life and physical symptoms in the general population: a dimensional analysis. Psychol Health. 2014;29(3):365-73.

39. Horwood S, Anglim J. A critical analysis of the assumptions of Type D personality : comparing prediction of health-related variables with the five factor model. Personal Individ Differ. 2017;117:172-6.

40. Widdershoven J, Kessing D. How are depression and Type D personality associated with outcomes in chronic heart failure patients? Curr Hear Fail Rep. 2013;10:244-53.

41. Denollet J, Pedersen S. Prognostic value of Type D personality compared with depressive symptoms. Arch Intern Med. 2008;168(4):431-2

42. Baron RM, DA K. The moderator-mediator variable distinction in social the moderator-mediator variable distinction in social psychological research: conceptual, strategic, and statistical considerations. J Pers Soc Psychol. 1986; 51(6):1173-82.

43. Aroian LA. The probability function of the product of two normally distributed variables. Ann Math Stat. 1947:18:265-71.

44. Kasai Y, Suzuki E, Iwase T, Doi H, Takao S. Type D personality is associated with psychological distress and poor self-rated health among the elderly: a population-based study in Japan. PLoS One. 2013;8(10):e77918.

45. Van Dooren FEP, Verhey FRJ, Pouwer F, et al. Association of Type D personality with increased vulnerability to depression : is there a role for in $\mathrm{fl}$ ammation or endothelial dysfunction ? - the Maastricht study. J Affect Disord. 2016;189:118-25.

46. Phillip JT, Robert AB. Depression, anxiety, and cardiac morbidity outcomes after coronary artery bypass surgery: a contemporary and practical review. J Geriatr Cardiol. 2012;9(2):197-208

47. Abramson LY, Metalsky Gl, Alloy LB. Hopelessness depression: a theorybased subtype of depression. Psychol Rev. 1989;96(2):358-72.

48. Smith PJ, Attix DK, Weldon BC, Monk TG. Depressive symptoms and risk of postoperative delirium. Am J Geriatr Psychiatry. 2016;24(3):232-8.

49. Denollet J, Pedersen SS, Ong ATL, Erdman RAM, Serruys PW, Van Domburg RT. Social inhibition modulates the effect of negative emotions on cardiac prognosis following percutaneous coronary intervention in the drug-eluting stent era. Eur Heart J. 2006;27(2):171-7.
50. Hur S, Han G-S, Cho B-J. Changes in glucose, TNF-a and IL-6 blood levels in middle-aged women associated with aerobic exercise and meditation training. J Phys Ther Sci. 2014;26(12):1933-6.

51. Denollet J, Conraads VM, Brutsaert DL, De Clerck LS, Stevens WJ, Vrints CJ. Cytokines and immune activation in systolic heart failure: the role of Type $D$ personality. Brain Behav Immun. 2003;17(4):304-9.

52. Einvik G, Dammen T, Hrubos-Strøm H, et al. Prevalence of cardiovascular risk factors and concentration of C-reactive protein in Type D personality persons without cardiovascular disease. Eur J Cardiovasc Prev Rehabil. 2011; 18(3):504-9.

53. Van Craenenbroeck EM, Denollet J, Paelinck BP, et al. Circulating CD34 $+/ K D R+$ endothelial progenitor cells are reduced in chronic heart failure patients as a function of Type D personality. Clin Sci. 2009;117(4):165-72.

54. Denollet J, van Felius RA, Lodder $P$, et al. Predictive value of Type D personality for impaired endothelial function in patients with coronary artery disease. Int J Cardiol. 2018;259(2017):205-10.

55. Ritter C, Tomasi CD, Dal-Pizzol F, et al. Inflammation biomarkers and delirium in critically ill patients. Crit Care. 2014;18(3):1-6.

56. Hughes CG, Morandi A, Girard TD, et al. Association between endothelial dysfunction and acute brain dysfunction during critical illness. Anesthesiology. 2013;118(3):631-9.

57. Denollet J, Schiffer AA, Spek V. A general propensity to psychological distress affects cardiovascular outcomes: evidence from research on the type D (distressed) personality profile. Circ Cardiovasc Qual Outcomes. 2010; 3(5):546-57.
Ready to submit your research? Choose BMC and benefit from:

- fast, convenient online submission

- thorough peer review by experienced researchers in your field

- rapid publication on acceptance

- support for research data, including large and complex data types

- gold Open Access which fosters wider collaboration and increased citations

- maximum visibility for your research: over $100 \mathrm{M}$ website views per year

At $\mathrm{BMC}$, research is always in progress.

Learn more biomedcentral.com/submissions 